\title{
Eurytoma sp. - agente promissor para o controle biológico do araçazeiro no Havaí
}

\author{
Charles WiKLer * \\ J. H. Pedrosa-Macedo**
}

\begin{abstract}
RESUMO
Uma espécie do gênero Eurytoma (Hymenoptera, Eurytomidae) causa a galhado-ramo do araçazeiro - Psidium cattleianum Sabine, 1821 (Myrtaceae). O inseto não foi identificado a nível de espécie, mas seus aspectos bioecológicos foram estudados em laboratório e em campo. É um possível agente para o controle biológico do araçazeiro que é planta daninha invasora em vários países. As coletas foram realizadas no primeiro planalto do Paraná. Estudou-se vários parâmetros de Eurytoma sp.: forma, cor, número de segmentos do corpo, largura da cabeça, comprimento do corpo, mortalidade e ciclo de desenvolvimento na fase larval; duração, tamanho, comprimento na fase pupal; cópula, proporção sexual, longevidade de machos e fêmeas, comportamento no acasalamento e alimentação na fase adulta. A galha é um dos fatores limitantes do araçazeiro, sendo a atividade larval a principal causa de danos na planta. Durante o ano seguinte à emergência do adulto, a galha seca, todas as folhas caem e o ramo morre, estabilizando o crescimento do araçazeiro.
\end{abstract}

Palavras-chave: Eurytoma sp., araçazeiro, controle biológico de plantas daninhas, galha

\section{ABSTRACT \\ Eurytoma sp. - agent promising for biological control of strawberry guava} in Hawaii. A species from Eurytoma (Hymenoptera, Eurytomidae) genus causes a gall in the stems of strawberry guava - Psidium cattleianum Sabine, 1821 (Myrtaceae). The insect was not identified in the specie level, but its biecological aspects were studied in laboratory and fields conditions, seeking the possible use as specific natural enemy of the strawberry guava. Sample collection was done in the first plateau of Paraná State, natural occurrence area of the plant. It was determined the following parameters for Eurytoma sp.: shape, color, number of segments of the body, width of the head, length of the body, mortality, development in larval phase, duration, size, development and length in pupa phase, and copulation, sexual rate, longevity of males and females, copulation behavior and feeding in the adult phase. The gall is one of the limiting factors of strawberry guava, being the larval activity of Eurytoma sp. the main cause of the damages. After the first year of adult emergence, the gall dries out and in the next year the stem dies, stabilizing the strawberry guava growth.

Key words: Eurytoma sp., biological control of weeds, strawberry guava, galls 


\section{INTRODUÇÃO}

O araçazeiro - Psidium cattleianum Sabine (Myrtaceae) é uma planta nativa das regiões sul e sudeste do Brasil. Encontra-se difundido em outras regiões tropicais e subtropicais onde tornou-se uma planta daninha invasora muito agressiva. No Havaí, foi introduzida intencionalmente por volta de 1825 , devido às condições adequadas para sua dispersão como solo fértil, clima favorável e a falta de inimigos naturais. Assim tornou-se uma das mais importantes plantas daninhas, pela abrangência da área infestada e seu potencial de impacto ambiental. Sua rápida dispersão foi favorecida por pássaros e outros animais selvagens.

SMITH (1985) classificou o araçazeiro entre as dez plantas daninhas mais agressivas do arquipélago havaiano. Para deter e regular a sua densidade populacional tornou-se necessário o seu controle com a utilização de inimigos naturais como insetos e patógenos, agentes capazes de realizar esta difícil tarefa.

A busca destes inimigos naturais para o controle biológico começou nos anos 80 com observações nas áreas de restinga do litoral brasileiro, do Espirito Santo ao Rio Grande do Sul.

HODGES (1988) obteve as primeiras informações sobre agentes potenciais para o controle biológico do araçazeiro e assim recomendou a realização dos estudos na região sul do Brasil. Sugeriu o Paraná como o local que melhor reunia condições para a realização dos estudos, face a presença das variedades de araçazeiro de frutos vermelhos e de frutos amarelos. Ainda por sua sugestão iniciava-se o programa cooperativo de pesquisas entre a Universidade do Havaí em Manoa e a FUPEF - Fundação de Pesquisas Florestais do Paraná, para a busca sistemática dos inimigos naturais do araçazeiro. Em março de 1991 foi firmado o Convênio FUPEF - Universidade do Havaí a execução do programa proposto que incluíra pesquisas de campo e de laboratório.

Nesse mesmo ano diversos trabalhos foram iniciados e, os aspectos bioecológicos de uma espécie do gênero Eurytoma, causadora da galha-doramo do araçazeiro estavam entre os objetivos de estudos previstos.

As metas realizadas para atingir este objetivo foram: coleta de material entomológico no campo; identificação da espécie através auxílio de especialistas; caracterização dos principais aspectos de todas fases vitais do euritomídeo; verificação e observações para comprovar se outras mirtáceas eram suas hospedeiras; descrever as características e consequiências dos danos ao araçazeiro e finalmente avaliar o grau de potencialidade do euritomídeo como agente no controle biológico. 


\section{MATERIAL E MÉTODOS}

As coletas de material vegetal e entomológico foram realizadas no Primeiro Planalto paranaense, caracterizado por altitude entre 650 a 1.100 metros e temperatura média anual variando de 15 a $19^{\circ} \mathrm{C}$, mínimas absolutas entre -5 a $-10^{\circ} \mathrm{C}$. O clima é submontano, temperado quente e úmido e muito úmido, com precipitação média anual entre 1.250 e $2.500 \mathrm{~mm}$ com distribuição uniforme e média de 179 dias de chuva, segundo MAACK (1968). De acordo com a classificação de Köppen, o clima da região pertence ao tipo $\mathrm{Cfb}$, sempre úmido com chuvas abundantes e distribuídas ao longo do ano, clima pluvial quente temperado e as estações são bem caracterizadas. Pelo sistema de classificação de zonas de vida de Holdrige, a região encontra-se na Floresta úmida Montana Baixa Subtropical. A vegetação é a típica de floresta ombrófila - mista de araucária e latifoliadas - e campos submontanos, CARPANEZZI (1986).

Nas áreas previamente determinadas foram selecionadas 60 árvores sadias em cujos ramos haviam galhas secas e em desenvolvimento. Estas árvores estavam distribuídas:

- Colombo, Estância Betânia -12

- Curitiba, Centro Politécnico - 18

- Curitiba, Viveiro da Escola de Florestas - 2

- Piraquara, Chácara Chantecler - 3

- Piraquara, Manancial da Serra - 25

As coletas de materiais foram realizadas semanalmente nesses locais, para se obter um fluxo contínuo no laboratório. Coletou-se ramos com galhas desde recém formadas até aquelas em estado de decomposição. Algumas vezes somente as galhas foram coletadas, depositadas em sacos de polietileno e acondicionadas dentro de caixa de isopor. Com este procedimento mantinha-se o material fresco durante o transporte do campo para o laboratório. No laboratório as bases dos ramos, com galhas, eram descascados, flambadas e colocados em recipientes contendo solução de açúcar e água na proporção de $20 \mathrm{~g}$ por $100 \mathrm{ml}$. Os recipientes foram mantidos em câmara climatizada, temperatura $22^{\circ} \mathrm{C} \pm 2{ }^{\circ} \mathrm{C}$, fotoperíodo 12 horas e umidade relativa de $70+$ $10 \%$. Para manter a absorção da solução a cada dois dias, as bases dos ramos eram limpas, cortadas flambadas e a solução substituída.

Alguns insetos adultos foram coletados no campo e colocados em recipientes plásticos transparentes forrados no fundo com papel filtro e na tampa uma abertura com filó para a aeração. Os adultos que emergiam no laboratório serviram para observações sobre acasalamento, postura e longevidade. Os mesmos foram alimentados com solução de água, dextrosol e mel na proporção de 10 por $50 \mathrm{~g}$ por $100 \mathrm{ml}$ e eram tratados diariamente.

Foram remetidas 10 fêmeas e 12 machos ao Prof. Dr. Vinalto Graf do Departamento de Zoologia da Universidade Federal do Paraná. Ao Dr. Luís de Santis do Museu de La Plata, na Argentina, foram enviados 5 casais. Para o Dr. 
J. La Salle do Instituto Internacional de Entomologia enviou-se 4 fêmeas e 4 machos. Todos estes exemplares foram enviados para a identificação da espécie.

Os ramos com sinais de posturas, foram coletados e levados ao laboratório para ser examinados ao microscópio estereoscópio.

Os ovos foram coletados nos ramos, onde haviam sido observadas as posturas.

As larvas foram obtidas após a abertura das galhas com auxílio de estilete. Em seguida eram cozidas em água a $100^{\circ} \mathrm{C}$, durante 5 minutos e conservadas em álcool a 70\% para as observações morfológicas, biológicas e medições.

As pupas foram retiradas das galhas e colocadas em placas de Petri para serem examinadas ao microscópio estereoscópio. Os parâmetros estudados foram: tamanho, coloração e duração da fase pupal.

\section{RESULTADOS E DISCUSSÃO}

Os especialistas identificaram o causador da galha-do-ramo na seguinte posição sistemática:

Ordem: Hymenoptera

Subordem: Apócrita

Superfamília: Chalcidoidea

Família: Eurytomidae

Gênero: Eurytoma

Espécie: Eurytoma sp.

Sobre o gênero Eurytoma descrito por Illinger em 1807 há na bibliografia referências de inúmeras espécies fitófagas e há outras parasitóides.

Segundo CLARIDGE (1961), Eurytoma é o gênero mais antigo descrito na família e um grande número de espécies têm sido descritas. $\mathrm{O}$ autor menciona que os limites genéricos são difíceis de distinguir e o autor achou impossível diagnosticar completamente os caracteres para identificação em chave sem um reconhecimento do grupo das espécies.

BUGBEE (1967), cita que as descrições e características do gênero Eurytoma são baseados somente em conhecimentos das espécies norteamericanas. O número de espécies deve estar próximo de 450 descritas. O mesmo autor em seu trabalho cita 33 espécies como parasitóides de insetos e 12 espécies fitófagas, mas os hábitos das espécies remanescentes são desconhecidos ou incertos.

BURKS (1971), cita que o gênero Eurytoma é o maior e mais difícil de ser identificado na família Eurytomidae, que inclui centenas de espécies por todo o mundo. Muitas destas espécies são classificadas como Eurytoma, não porque são provavelmente a espécie-tipo, mas porque ainda não foi possível 
classificá-los em outra posição sistemática. Quase todas as características genéricas de Eurytoma são consequentemente, sujeitas a exceções.

Os resultados mostraram que a hipertrofia do ramo começa com a oviposição. As células vegetais ao redor do local onde o ovo foi colocado, proliferam, cobrindo o orifício e envolvendo completamente o ovo (WIKLER, 1995). As galhas-do-ramo são uniloculares. A coloração inicial do ramo é verde, porém com o desenvolvimento da planta, o ramo vai tornando-se escuro e finalmente marrom. A forma das galhas varia de levemente dilatada à arredondada, com diversas formas intermediárias. $\mathrm{O}$ tamanho das galhas variou de 0,6 a 2,1 centímetros de comprimento por 0,3 a 0,9 centímetros de largura.

Segundo CLARIDGE (1961) o desenvolvimento das galhas começa logo que a larva sai do ovo e começa a alimentar-se. Este fato foi confirmado neste trabalho diversas vezes, quando se observou-se larvas neonatas.

Nas fases iniciais as galhas são maciças internamente e as larvas ficam confinadas ao espaço necessário para seu desenvolvimento. Na época de emergência dos adultos, a parede das galhas fica com espessura entre 1,0 e 1,5 milímetros. As fêmeas fazem as posturas nos ramos entre os meses de outubro e janeiro, e o adulto que se formará nesta galha apenas emergirá aproximadamente no mesmo período do ano seguinte. A partir da emergência do adulto, o crescimento da planta é interrompido e, devido à galha o fluxo normal de seiva é impedido. Com isto, os ramos param de crescer, secam e morrem.

Em dois anos o ramo morre, sendo um ano desde a formação da galha após a postura até a emergência do adulto e mais um ano para que a galha seque totalmente.

Durante o trabalho foram observadas 60 árvores infestadas com o euritomídeo. Em 28 destas encontrou-se 177 galhas de diferentes tamanhos. A maior quantidade de árvores contendo galhas foi encontrada no município de Colombo na localidade Estância Betânia, Tabela 1. Entretanto a maior quantidade de galhas por árvores foi encontrada no município de Curitiba no Centro Politécnico com uma incidência média de 17 galhas por árvore. No município de Piraquara, na Chácara Chantecler a média de galhas por árvore foi de 4 galhas e no Manancial da Serra a média por árvore foi de 3,37 galhas, Tabela 1. 
Tabela 1 - Quantidade de galhas formadas por euritomídeo nas quatro localidades

Table 1 -Quantity of galls formed by euritomids in the four localities

\begin{tabular}{lccc}
\hline Localidade & № de árvores & № de galhas & Média galhas/árvore \\
\hline Curitiba - C. Politécnico & 5 & 85 & 17,00 \\
Piraquara - C. Chantecler & 4 & 16 & 4,00 \\
Colombo - E. Betânia & 11 & 49 & 4,45 \\
Piraquara - M. da Serra & 8 & 27 & 3,37 \\
\hline Soma & 28 & 177 & 6,32 \\
\hline Média Geral
\end{tabular}

As alturas de localização das galhas no araçazeiro variam entre 20 a 190 centímetros. Na maioria dos ramos observados, as galhas eram formadas próximas uma das outras, provavelmente pela preferência das fêmeas aos saltos do que aos vôos.

A fêmea geralmente põe os ovos individualmente nos ramos novos do araçazeiro e a postura pode ser feita no mesmo ramo, porém não muito próximo um local de outro.

O ritual de postura foi observado e acompanhado uma única vez o que se deu no município de Colombo, na Estância Betânia. A fêmea pousa no ramo, tateia-o varias vezes de cima para baixo com as antenas e, assim escolhe o local da postura. Após definido este, apoia-se firmemente nas patas posteriores, movimenta-se o abdome de forma circular, introduz livre e suavemente o duto ovipositor no interior da casca. O abdome e o duto ovipositor formam um ângulo de 90 graus. O tempo deste ritual e o término da postura é, em média, de 5 minutos.

Segundo ASKEW (1984), depois da postura, o ovo fica geralmente alojado no tecido da planta. Imediatamente após a larva sair do ovo, os tecidos da planta ao redor são reduzidos a uma pequena bolsa, que forma a câmara larval. As células ao redor da câmara larval proliferam e fecham a abertura externa, então a larva fica completamente fechada (MAGNUS citado por ASKEW (1984).

Os ovos são elípticos, levemente arredondados em um lado e apoiados por uma haste, de aproximadamente $0,2 \mathrm{~mm}$ de comprimento. Eles são opacos e de coloração branca, tornando-se marrom após alguns minutos a postura. A observação de ovos no campo é muito difícil, somente uma vez em agosto de 1994 foram observados e coletados no município de Colombo, na Estância Betânia.

O ovo recém posto é difícil de ser localizado devido sua coloração e o local onde está inserido. Pode ser visto apenas com a ajuda de um microscópio estereoscópio. Não registra-se nenhuma postura em condições laboratoriais.

As larvas são brancas, apodas, curvas e em geral apresentam a forma de "C" '. As mandíbulas são esclerosadas de cor marrom, postas, com as quais raspam o tecido da galha para alimentação e posteriormente para fazer o orifício de emergência. 
As larvas tem 13 segmentos no corpo, o comprimento varia entre 1,23 a 5,20 milímetros e a cápsula cefálica varia ente entre 0,32 a 0,64 milímetros.

Todas as larva morreram quando as galhas foram abertas. O desenvolvimento larval dos euritomídeos ocorre em geral, em 5 ínstares. A larva é finíssima no primeiro ínstar. No segundo e terceiro ínstares, as larvas são alargadas, semi-transparentes e quase estáticas. No quarto ínstar e sobretudo no quinto possuem forma de barril, são pouco móveis e bem desenvolvidas, se alimentam da seiva da planta, ferindo com as mandíbulas as paredes da galha. Acompanhou-se o desenvolvimento de 60 larvas em laboratório, 48 morreram e apenas 12 chegaram à fase pupal.

Portanto a mortalidade nesta fase, em condições de laboratório, foi considerada elevadíssima.

A pupa é do tipo livre ou exarata, têm os apêndices livres, não colados ao corpo, assemelhando-se ao adulto pálido e mumificado. Os principais caracteres dos adultos podem ser vistos nesta fase devido a pupa ter um tegumento fino e transparente.

No laboratório a duração da fase pupal variou de 9 a 15 dias. CARRILLO \& DICKASON (1963) obtiveram a média de 7,9 dias para indivíduos de outra espécie do gênero Eurytoma criados em Oxalis latifolia H.B.K. - trevo vermelho.

A pupa conserva a coloração branca da larva até aproximadamente dois dias após o empupamento. Daí algumas áreas do corpo começam a escurecer e tomar a coloração marrom. $\mathrm{O}$ fenômeno do escurecimento inicia-se pela cabeça, em seguida o tórax e por último as pernas. Assim a pupa passa a ter a coloração negra do adulto. Quando se atinge a maturação pupal, o inseto libera-se do tegumento pupal, exceto a parte que cobre as antenas, da qual só é libertada após a emergência.

Para facilitar a emergência de adultos no laboratório foram mantidas galhas a uma umidade de $70 \pm 10 \%$, umidade essa suficiente para manter os ramos vivos e também as galhas. Nos casos em que as galhas iniciavam a secar, fazia-se um corte longitudinal, o que facilitava a emergência dos adultos. Foi observado que os euritomídeos adultos escavam os orifícios com suas mandíbulas e com as patas posteriores puxam os restos para trás. Os orifícios de emergência são perfeitamente redondos. A emergência pode durar vários dias e houve caso em que o euritomídeo morreu antes de emergir.

$\mathrm{O}$ adulto é de coloração negra e dentre suas principais características destacam-se o tórax grosseiramente pontuado e o pronoto grande e quadrado. Visto dorsalmente é quase tão largo quanto a cabeça e o mesonoto. As asas são claras e transparentes, as antenas freqüentemente são pilosas.

Os principais caracteres para a separação de sexos são: as antenas, o tamanho e a presença do duto ovipositor da fêmea. Os caracteres de machos e fêmeas concordam com as descrições feitas por BUGBEE (1936) em vários aspectos: o escapo da antena da fêmea mede aproximadamente um terço do resto do comprimento; o flagelo tem a forma filiforme e segmentado em 7 partes, os segmentos são mais largos do que compridos; a antena do macho tem 
como aspecto característico o escapo masculino ter em média um quarto do tamanho total da antena e é mais reforçado do que o escapo feminino; a quantidade de pelos sensoriais vai raleando gradativamente no sentido dos segmentos terminais.

Foram coletados 132 adultos, 79 eram fêmeas e 53 machos, cuja razão sexual aproxima de 0,7 o que concorda com as afirmações de vários autores que citam as fêmeas de euritomídeos como predominantes na frequiência sobre os machos. Os machos variam de tamanho entre 1,6 a 1,9 milímetro de comprimento e as fêmeas 1,7 a 3,9 milímetros. A longevidade máxima, em laboratório foi de 16 dias. 12 casais formados a partir desses adultos foram mantidos em cativeiro durante todo período de vida e apenas 4 casais não copularam. Os demais copularam durante o período diurno, porém as fêmeas não realizaram posturas.

No início da primavera é abundante a ocorrência do adulto, porém as condições climáticas do local é imprescindível para o seu desenvolvimento. Observou-se apenas uma geração por ano. $\mathrm{O}$ ciclo biológico das diferentes fases de vida do euritomídeo está resumido na figura 3. Adultos e ovos são encontrados no período de setembro a fevereiro. As larvas são encontradas de fevereiro a julho e as pupas são encontradas a partir de junho até agosto (WIKLER, 1995).

Figura 1 - Época de ocorrência dos diferentes estágios de Eurytoma sp. causador da galha-do-ramo em P. cattleianum, curitiba, PR. 1994

Figure 1 - Occurrence of the differente stages of Eurytoma sp., stem gall causer in P. cattleianum,Curitiba, PR.1994

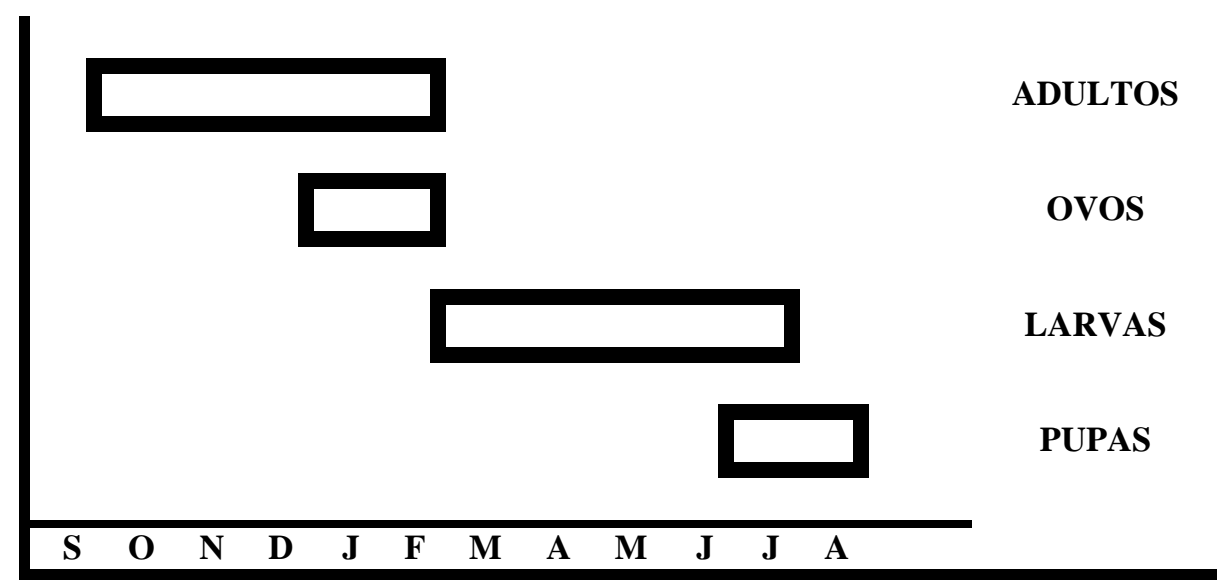

Observou-se que nos ramos do araçazeiro, onde existem galhas causadas pelo euritomídeo, não há floração. A presença da galha no ramo impede o fluxo normal da seiva e consequentemente este é debilitado por inanição até chegar a sua morte. 
Em outras mirtáceas tais como goiabeira - Psidium guajava, pitangueira - Eugenia uniflora, Eucalyptus sp. e gabirobeira - Campomanesia xanthocarpa, não foi registrada a presença de galhas de Eurytoma sp. e nem mesmo foram vistos adultos nessas plantas.

\section{CONCLUSÕES}

Nas condições experimentais nas quais as pesquisas foram conduzidas, conclui-se que:

a) o causador da galha-do-ramo em Psidium cattleianum foi identificado como Eurytoma sp. e é um agente limitante de seu desenvolvimento;

b) durante o período em que Eurytoma sp. se encontra dentro da galha não foram encontrados inimigos naturais;

c) o melhor parâmetro do dimorfismo sexual são as antenas;

d) não ocorre floração e frutificação nos ramos com galhas do Eurytoma sp.;

e) a morte do ramo do araçazeiro ocorre um ano após a emergência do adulto de Eurytoma sp.

f) não foi verificada a presença de galhas causadas por Eurytoma sp. em outras mirtáceas;

g) o comprimento médio de galha foi 13,5 $\mathrm{mm}$ e o diâmetro médio foi de $6 \mathrm{~mm}$;

h) o período de postura ocorre entre os meses de outubro a janeiro;

i) a duração entre a postura e a emergência do adulto é de aproximadamente um ano.

\section{BIBLIOGRAFIA CITADA}

ASKEW, R. R. 1984. The Biology of Gall Wasps. In: ANANTHAKRISHNAN, T. N. Biology of gall insects. New Delhi: Oxford \& IBH. 361 p.

BUGBEE, R. E. 1936. Phylogeny of some Eurytomid genera. Entom. Amer., 16(n.s.):169-223, 6 ests., 1 fig.

BUGBEE, R. E. 1967. Revision of the chalcid wasps of the genus Eurytoma in America north of Mexico. Proc. U. S. Nat. Museum. 118:433-552.

BURKS, B. D. 1971. A Synopsis of the genera of the family Eurytomidae (Hymenoptera: Chalcidoidea). Trans. Amer. Ent. Soc., Vol. 97, pp. 1-89.

CARPANEZZI, A. A. et al. 1986. Zoneamento ecológico para plantios florestais no Estado do Paraná. Brasília, EMBRAPA-DDT, 89 P. (EMBRAPA-CNPF: Documentos, 17). 
CARRILLO, J. L. \& DICKASON, E. A.1963. Biology and economy importance of seed chalcids infesting red clover and alfafa in Oregon.Technical Bulletin. Agricultural Experiment Station. Oregon State University, n. 68, p. 1-35.

CLARIDGE, M. F. 1961. An Advance Towards a Natural Classification of Eurytomid Genera (Hym., Chalcidoidea), with Particular Reference to British Forms. Trans. Soc. Brit. Ent. 14: 167-185.

HODGES, C. S., Jr. 1988. Preliminary Exploration for potential Biological Control agents for Psidium cattleianum. Technical Report 66. Cooperative National Park Resources Studies Unit, Dept. of Botany, University of Hawaii, Honolulu. 32 pp.

MAAK, R. Geografia Física do Estado do Paraná. Curitiba, CODEPAR. 50 p. 1968.

SMITH, C. W. 1985. Impact of alien plants on Hawai'i's native biota. In: Hawaii's Terrestrial Ecosystems: Preservation and Management, pp. 180-250. C. P. Stone \& J. M. Scott (eds.) Cooperative National Parks Studies Unit, Honolulu, Hawaii.

WIKLER, C. 1995. Aspectos Biológicos e Morfológicos de Eurytoma sp., causador da galha do ramo do araçazeiro - Psidium cattleianum SABINE, 1821. Dissertação de Mestrado. Universidade Federal do Paraná. 62 p. 